\title{
ROCK AND ROLL, JOHN LENNON E A ESFERA PÚBLICA
}

No início dos anos 1970, John Lennon foi ostensivamente espionado pelo Federal Bureau of Investigation (FBI) a pedido de Richard Nixon. A inclinação esquerdista de Lennon era evidente, no entanto a sua atuação se devia ao lugar que ocupava no panteão do rock and roll, algo bem distante de sua capacidade de influir sobre estratégias de organização e mobilização política. Agentes do FBI comprometidos com a vigilância ao ex-Beatle escreviam em seus relatórios, ou manifestavam particularmente a interlocutores, que ele não era uma ameaça aos poderes interessados em sua atemorização. Como foi amplamente divulgado desde então, as medidas persecutórias a Lennon culminaram em um penoso e altamente questionável processo de deportação sob a alegação do crime de uso de drogas (haxixe) na... Inglaterra!

As agências de investigação e repressão seguiam a orientação de que o músico poderia contribuir para desestabilizar a campanha presidencial americana e, por seus vínculos com consagrados contestadores, supostamente alimentar conflagrações semelhantes àquelas ocorridas em I968 durante a Convenção do Partido Democrata em Chicago. Se John Lennon não era um quadro político em sentido estrito, quais os recursos que ele detinha a ponto de se tornar uma preocupação para as autoridades? A resposta não está em suas "ligações perigosas".

John Lennon era admirado e amado no mundo inteiro. Suas canções e atitudes, desde os anos I960, permaneciam vivas para multidões, assim como 
os Beatles foram amados por gente de todas as idades e das mais variadas preferências políticas, culturais e musicais. Com sua inquietude tornou-se um protagonista na esfera pública a ponto de ter sido nomeado um dos homens do ano de 1969 pela revista Rolling Stone, editada internacionalmente, e um dos homens da década escolhido pela ATV britânica, junto com John Kennedy e Ho Chi Minh.

O capital político de John Lennon figurava mais nos cálculos das forças do conservadorismo do que nas suas disposições pessoais. Era um artista movido por paixões, indignações e críticas lançadas a partir de entusiasmos e angústias, em vez de uma linha política concebida na direção de objetivos previamente definidos. Certamente ele não se furtava em declarar suas adesões, como na campanha pela libertação de Angela Davis e de John Sinclair, dois proeminentes esquerdistas americanos presos por motivos ridículos. Davis namorava um líder dos Panteras Negras e Sinclair havia sido condenado a dez anos de prisão pelo porte de dois cigarros de maconha fornecidos por uma policial disfarçada.

John Lennon jamais se prestou à domesticação de seus impulsos e opiniões. Teve um trajeto pleno de guinadas, surpresas, comportamentos contraditórios e pedidos de desculpas. Por essas razões, se o cânone adotado para perceber a sua atuação for a influência sobre os modos de governo ou a pretensão de poder, o mínimo que se pode dizer é que sua suposta e ameaçadora carreira política era "mal administrada". Pela enorme popularidade de ter sido um Beatle e a honestidade da exposição pública de seus questionamentos existenciais, John Lennon despertava essa movimentação patética e autoritária das agências de informação e repressão.

o que se busca aqui é aproximar o extraordinário apelo do rock and roll, que atravessa gerações desde a década de I950, com as intenções de mudança que explodiram nos anos I960 e I970, condensadas nas reviravoltas do percurso de John Lennon na esfera pública. Não se pretende fazer um resumo dos cenários de época, mas, em alguma medida, ambientar o leitor com fatos e significados que se afastam no tempo e merecem ser revisitados.

Nos anos i960 e I970, o universo do rock apresentou parentescos com a revolta e a indignação. O historiador Eric Hobsbawm descreveu-o como "o meio universal de expressão de desejos, instintos, sentimentos e aspirações do público entre a adolescência e aquele momento em que as pessoas se estabelecem em termos convencionais dentro da sociedade, família ou carreira; a voz e a linguagem de uma 'juventude' e de uma 'cultura dos jovens' consciente de seu lugar dentro das sociedades industriais modernas" (Hobsbawm, 2009:I8). E mais:

Poderia expressar qualquer coisa e tudo ao mesmo tempo dentro dessa faixa etária, mas embora o rock tenha desenvolvido variantes regionais, nacionais, de classes ou político-ideológicas claras, sua linguagem básica, da mesma 
forma que a vestimenta vulgar-populista associada à juventude (principalmente os jeans), atravessou fronteiras de países, classes ou ideologias. A exemplo do que ocorre na vida dos integrantes desses grupos etários, no rock o público e o privado, o sentimento e a convicção, o amor, a rebeldia e a arte, a dramatização e a postura assumida no palco não são distinguíveis uns dos outros (Hobsbawm, 2009: 18).

Um ciclo milionário de negócios foi ativado quando o rock se instalou de maneira irresistível na cultura de massa. Interpretações mais céticas, de "olhares que já viram tudo", reparam no fenômeno apenas o aproveitamento dessa criação artística como mais um campo a ser explorado no e pelo mercado. Mas essa postura analítica está longe de contar toda a história. Hobsbawm ressalta dimensões da efervescência musical que ultrapassaram as injunções econômicas e as flutuações do mercado capitalista, associadas aos ímpetos de mudança social e dos modos de vida que convulsionaram os costumes, as relações entre os gêneros, os tabus sexuais e as vias de integração ao sistema, sintetizadas na expressão "o que é pessoal, é político", oriunda do movimento feminista. O desafio às instituições vigentes e o questionamento das relações cotidianas esteve presente naquele momento de grande energia criativa do rock and roll. John Lennon foi uma das vozes mais ouvidas no período, com implicações nas narrativas tradicionalmente legitimadas na esfera pública. Com relação ao mercado e ao sentido da arte na sociedade, Hobsbawm adiciona:

Como muitas vezes acontece na história das artes, as principais revoluções artísticas não surgem a partir dos que se intitulam revolucionários, mas daqueles que empregam as novidades com propósitos comerciais (Hobsbawm, 2009: 22).

O crítico marxista norte-americano Fredric Jameson situa os Beatles e os Rolling Stones no "alto modernismo", momento em que os movimentos culturais ainda expressavam o mal-estar e a negação da modernidade (ao mesmo tempo em que davam continuidade a seus princípios), além de denotar um poder questionador e utópico. Na atual dinâmica societária, a cultura baseada na imagem (e na linguagem da televisão, das redes mundiais de computação, da publicidade etc.) suplantou a cultura literária anteriormente predominante e alimenta outras formas de cognição. Na atual "estetização da realidade" (expressão que Jameson toma emprestado de Walter Benjamin), a arte se mistura indissoluvelmente à compra e venda de produtos através da criação de narrativas que favorecem investimentos simbólicos dos consumidores em torno das mercadorias.

O imaginário, as pulsões da intimidade, as maneiras de ser e a mobilização dos sentimentos foram incorporados ao universo das mercadorias através de narrativas estéticas e da cultura. Para Jameson, isso evidencia uma "desdiferenciação" (o termo é de Jameson) entre a economia e a cultura, ou 
ainda, segundo outra expressão utilizada pelo autor, uma mudança profunda no interior do próprio modo de produção:

O que ocorreu é que a produção estética hoje está integrada à produção das mercadorias em geral: a urgência desvairada da economia em produzir novas séries de produtos que cada vez mais pareçam novidades (de roupas a aviões), com um ritmo de turn over cada vez maior, atribui uma posição e uma função estrutural cada vez mais essenciais à inovação estética e ao experimentalismo (Jameson, 1996:30).

O tempo nas narrativas midiáticas é marcado pelo "eterno presente" que resulta no "fim do estilo", no sentido do único e do pessoal, ou no "fim da pincelada individual distinta" (Jameson, 1996: 43) na prática de hábitos sociais e mentais com influência sobre a vida artística. Apesar de certo exagero que tal interpretação carrega (Jameson tem consciência, em suas palavras, de tal "dramatização"), ela permite um olhar retrospectivo sobre o momento do "alto modernismo" em que figuravam os Beatles e os Rolling Stones. Ou, se quisermos, sobre a explosão do rock nos anos I960 que proporcionou uma intensa renovação da linguagem da música popular. Jameson destina à década de todas as revoltas a caracterização de "extraordinário revival das representações utópicas" (Jameson, I996: I9), mas a investigação do cenário musical mostra mais do que isso. Com arrojo teórico mais sóbrio, e talvez por sua ambientação apaixonada no mundo do jazz, Hobsbawm percebeu uma variedade mais ampla de traços relevantes.

No início dos anos 1960, havia 250 bandas na Merseyside, região do rio Mersey, nos arredores de Liverpool. Uma boa parte de seus componentes eram garotos provenientes de famílias operárias, como George Harrison, cujo pai era um sindicalista atuante (Gould, 2009: I3I). Com a memória ainda viva das penúrias da Segunda Guerra Mundial, todos se empenhavam em ter um lugar na parada de sucessos e melhorar de vida. Apesar das muitas sagas desconhecidas de grupos que não tiveram carreiras significativas, ergueu-se uma arte que transmitia novas experiências de vida e carregava a "indistinção" apontada por Hobsbawm (público/privado, sentimento/convicção, amor, rebeldia etc.). No curso de poucos anos, a criação musical de meninos e meninas que adoravam e imitavam Little Richard, Chuck Berry e Elvis Presley alcançou patamares muito elevados. A linguagem musical se sofisticou rapidamente. Mantida a fidelidade aos velhos homens do blues americano, foi possível perceber, dentre inumeráveis exemplos, a presença de Chopin em "Because", do álbum Abbey Road, dos Beatles, e Bach nos arranjos vocais dos Beach Boys.

O mundo do rock não se constituiu apenas de uma combinação de sons, instrumentos e interpretações que formaram um gênero musical; também relata as vivências de uma geração e suas variadas manifestações. Terá sido comovente para muitos, sofrido para outros tantos e repugnante para mentes mais conservadoras. Muitos de seus maiores artistas já morreram como Jimi 
Hendrix, John Lennon, Janis Joplin, Brian Jones, Jim Morrison, Mama Cass, Keith Moon, Otis Redding, George Harrison, Marvin Gaye e Raul Seixas, entre outros. Dentre os que permanecem em atividade, parece um milagre que Keith Richards esteja de pé. Eles foram embora cedo demais, a maioria com menos de trinta anos, e alguns chegaram aos quarenta, como John Lennon. Vitimados por excesso de drogas, vidas vividas no limite ou por assassinato (nos casos de John Lennon e Marvin Gaye), produziram passagens memoráveis e continuam sendo ouvidos pelas gerações posteriores, renovando o gosto pela música e lembrando os sonhos daqueles agitados anos. Neste sentido, sondar o mundo do rock dos anos I960 e I970 visa aproximar o fogo que ardia na criação musical com os temas que povoaram a esfera pública.

Nos últimos cinco anos foram publicados no Brasil inúmeros livros sobre o rock das décadas de I960 e I970. Muito do que aqui está mencionado provém, de forma direta ou indireta, de biografias, coletâneas de entrevistas, gravações comentadas, ensaios sobre a cultura, ao lado de estudos mais densos como a já citada História social do jazz, de Eric J. Hobsbawm. Livros que trazem as gravações comentadas dos Beatles, dos Rolling Stones e de Bob Dylan são particularmente interessantes, especialmente The Beatles - a história por trás de todas as canções, de Steve Turner (Cosac Naify, 2009), que contém um material valioso e inspirador para outras investidas de pesquisa.

Outros títulos importantes são Vida, de Keith Richards, No direction home - a vida e a música de Bob Dylan, de Robert Shelton, Ponto final - crônicas sobre os anos I960 e suas desilusões, de Mikal Gilmore, John Lennon - a vida, de Philip Norman, Under their thumb - como um bom garoto se misturou com os Rolling Stones e sobreviveu para contar, de Bill German, Can't buy me love - os Beatles, a Grã-Bretanha e o Estados Unidos, de Jonathan Gould, As melhores entrevistas da revista Rolling Stone, editadas por Jann S. Wenner e Joe Levy, além de textos que abordam a inquietação política e social como I968 - Eles só queriam mudar o mundo, de Regina Zappa e Ernesto Soto, e O poder das barricadas - uma autobiografia dos anos 6o, de Tariq Ali. Uma quantidade enorme de sites na Internet merece ser vasculhada, evidentemente de valor muito desigual. Mas, às vezes, uma observação leiga pode estar "abençoada por um sexto sentido sociológico", comentário de Zygmunt Bauman sobre o trabalho de Decca Aitkenhead (2000: 17), repórter do The Guardian.

Documentários são fontes de informação preciosas, especialmente aqueles produzidos por destacados realizadores. A começar por Martin Scorcese, que filmou The last waltz (1978), No direction home - Bob Dylan (2005) e Shine a light (sobre os preparativos e a posterior apresentação dos Rolling Stones no Beacon Theatre de Nova York, 2008), que trazem excelentes retratos de época e do ambiente musical do rock. Também merecem ser vistos U. S. versus John Lennon (de David Leaf \& John Scheinfeld, 2006), A sexta face do Pentágono (do consagrado documentarista Chris Marker, 1967), Standing in the 
shadows of Motown (de Paul Justman, 2002), Stones in exile (de Stephen Kijak, 20Io) além dos inevitáveis Woodstock (dirigido por Michael Wadleigh e editado por Martin Scorcese, I970), Gimme Shelter (sobre o Festival de Altamont, dirigido por Albert Maysles e Charlotte Zwerin, 1970) e Let it be (dirigido este por Michael Lindsay-Hoog, I970).

Nessa breve reconstituição, ouvir é tão importante quanto ler. Deixar-se transportar pelas canções permite absorver, sem pressa, o impacto das palavras e das sonoridades favorecendo o misterioso trabalho da memória e a ambientação nos cenários sugeridos pelas trilhas musicais. Esse material ajudou a produzir hipóteses de trabalho, muitas delas descartadas, até a fixação no trajeto de John Lennon como exemplo destacado das afinidades entre o mundo do rock and roll, as mudanças políticas e culturais e seu papel distintivo na esfera pública.

\section{MENOS QUE REVOLUÇÃO, MAIS QUE ENCENAÇÃO}

Max Weber gostava de dizer "minha função é exagerar". Como é reiterado em sua obra através da orientação metodológica dos "tipos ideais", o exagero permite observar os traços fundamentais dos fenômenos ressaltando o que não parece distinguível nos casos atenuados. O parentesco de John Lennon com a militância política, observado no final dos anos I96o e início dos anos I970, pode ilustrar situações de engajamento menos explícito ou trajetos musicais no cenário do rock and roll aparentemente desvinculados da contestação que sacudiu a época.

O panteão dos ídolos da música popular esteve repleto de artistas distantes da política, no entanto suas diversificadas fontes de criação expressavam muito do Zeitgeist, o espírito do tempo. O rock and roll fez parte da atmosfera eletrizante marcada pelo desejo de mudança e trouxe uma revolução na linguagem musical que se somou à revolução sexual, à revolução dos costumes e à ampliação do horizonte de escolhas de vida pela politização de outras esferas da existência humana. O encantamento proporcionado pelas canções e pelo som das guitarras elétricas fez coro às palavras de ordem, ao barulho das manifestações e às disposições íntimas de experimentar novos vínculos. Era possível sentir o tempo que se vivia nas faixas dos discos dos artistas preferidos.

Como muita gente chegou a acreditar naqueles anos, o rock and roll não foi a "música da revolução", mas se constituiu na trilha sonora que familiarizou grandes parcelas de jovens (mesmo aqueles mais afastados de ideários políticos ou orientações ideológicas contra o status quo) com uma pluralidade de formas de contestação. As paradas de sucessos da época também ecoavam os generosos ímpetos que inauguravam uma ordem de desejos como aqueles estampados nos muros de Paris, em plena agitação do mês de maio de I968, que diziam "a felicidade é uma ideia nova". 
Associações diretas entre músicos de rock e militantes da revolução foram episódicas, proporcionadas mais pelo borbulhar do caldeirão da época do que uma decorrência da aproximação de ideias e ação na busca de objetivos políticos. Ninguém deu bola à tenda dos revolucionários no Festival de Woodstock, onde se encontrava, entre outros, Abbie Hoffman, dirigente maior do Youth International Party, um extravagante grupo esquerdista também conhecido por mobilizações que se confundiam com happenings. Na ocasião, Pete Townshend, do The Who, expulsou Hoffman do palco com golpes de sua guitarra. Tempos depois, arrependido, Townshend lamentava: "Minha reação foi mais intuitiva do que reflexiva. O que Abbie disse era correto em muitos sentidos" (Merheb, 2012: 426).

Country Joe Mc Donald, que se apresentou no festival com sua banda "Country Joe and the Fish", era filho de velhos militantes comunistas, havia lutado no Vietnã e pregava abertamente a derrubada do sistema. Foi muito aplaudido, mas não chegou a incendiar o ambiente ou ganhar destaque especial com sua performance. Já Jimi Hendrix é lembrado até hoje pela interpretação do hino americano reproduzindo o barulho das bombas lançadas no Vietnã. Em outras ocasiões, Hendrix chegou a fazer contribuições ocasionais de dinheiro para os Panteras Negras, mas a sua revolução estava na maneira totalmente inovadora de explorar os limites sonoros da guitarra.

Perde-se o melhor do que aconteceu naqueles anos se o olhar se fixar apenas nas afinidades necessárias entre a música popular e a política. Um vasto campo de experiências sociais foi aberto pelos levantes políticos e culturais que deixaram como legado a memória e as motivações para a ação de quem desejava viver de um modo diferente. O rock and roll esteve misturado a esses acontecimentos de maneira muito variada. Um antecedente importante foi a célebre apresentação de Elvis Presley na televisão americana em I956, que lhe valeu a denominação de "Elvis, the pelvis" pelo movimento de seus quadris na interpretação das canções. O impacto da aparição de Elvis nos lares americanos foi um verdadeiro escândalo para os padrões conservadores da época, e não se pode dizer que havia intenções políticas na arte daquele garoto branco do Sul dos Estados Unidos.

A análise destinada à busca de causalidades imediatas entre as grandes correntes da movimentação política e o cenário do rock and roll tende a produzir aproximações sumárias ou de correspondência entre os dois campos, mas não esclarece nexos mais sutis e menos aparentes. Ou, em outra versão, a postura marcada pelo "realismo decepcionado" apenas lamenta o curso dos fatos pelo amortecimento do impacto da música popular e dos desejos de mudança pela "sombra do mercado". Esta tende a rotular a aproximação entre o passado recente e o presente como "nostalgia". O resultado dessas interpretações é o mesmo: a minimização dos fluxos de inquietação sobre a atividade artística e das repercussões, muitas delas bizarras ou estranhas aos roteiros 
consagrados, que acompanharam as décadas de revolta. A recusa nostálgica tem a intenção de deixar-se arejar pelo novo, livre de fixações obsessivas no que já ficou para trás, mas deixa de fora coisas demais.

Se na política os ideais libertários não mudaram as instituições como se desejava, ensejaram, nas palavras de Olgária Matos em "Tardes de maio", uma "imitação sincera" da revolução (Matos, I998: I7), que não merece apenas um olhar condescendente de realistas "atentos" ao desenrolar histórico. O rock and roll também documentou o "ensaio" de novas formas de viver, mesmo para aqueles que viam a política como algo estranho às suas motivações.

A repercussão do rock and roll junto à juventude dos anos I960 e 1970 permitiu a familiarização e a divulgação de sentidos da mudança que se exprimiram para além da linguagem da política. Traços desafiadores e inconformistas atravessaram as décadas posteriores, o que ajuda a entender a longevidade e a popularidade de setentões como os Rolling Stones, Paul McCartney, Eric Clapton e de tantos outros, apesar dos hits não aparecerem com a frequência de então.

Assim, em vez de estabelecer afinidades necessárias entre a música e a política, pode-se apreciar as "afinidades eletivas" entre configurações sociais distintas. O conceito foi explorado nos estudos de Michael Löwy, marxista atento à fertilidade da obra de Max Weber. Entre outras passagens da obra de Weber, as "afinidades eletivas" aparecem em A ética protestante e o espírito do capitalismo. Uma aproximação, ainda muito geral, aparece em Redenção e utopia:

Designamos por "afinidade eletiva" um tipo muito particular de relação dialética que se estabelece entre duas configurações sociais ou culturais não redutível à determinação causal direta ou "influência" no sentido tradicional (Löwy, I989: I3, grifos no original).

O primeiro ponto a ser destacado é a relação entre duas configurações sociais ou culturais que não se estabelece por causalidade direta ou influência em seu sentido corriqueiro, tratamento fiel às considerações de Weber relativas à singularidade dos fenômenos e da negação a priori de determinações "materiais" ou "espirituais" como orientação metodológica. Em A ética protestante... são mencionados, por exemplo, os elementos convergentes e análogos entre uma ética religiosa e um comportamento econômico. Maior aprofundamento da compreensão das "afinidades eletivas" aparece no ensaio "Sobre o conceito de 'afinidade eletiva' em Max Weber", onde Löwy ressalta o seu rendimento teórico para uma Sociologia da Cultura:

Propomos, então, a seguinte definição, partindo do uso weberiano do termo: afinidade eletiva é o processo pelo qual duas formas culturais - religiosas, intelectuais, políticas ou econômicas - entram, a partir de determinadas analogias significativas, parentescos íntimos ou afinidades de sentidos, em uma relação de atração e influência recíprocas, escolha mútua, convergência ativa e reforço mútuo (Löwy, 2011: 139). 
E mais:

Parece-me que o conceito de afinidade eletiva pode se aplicar a muitos domínios. Ele permite compreender - no sentido forte de Verstehen - um certo tipo de conjunção entre fenômenos aparentemente disparatados dentro de um mesmo campo cultural (religião, política e economia) ou entre esferas sociais distintas: religião e economia, misticismo e política etc. O conceito dá conta de processos de interação que não são revelados nem pela causalidade direta, nem pela relação "expressiva" entre forma e conteúdo (por exemplo, uma forma religiosa sendo a "expressão" de um conteúdo político ou social), nem, tampouco, pela "função" de uma parte em meio à totalidade social (Löwy, 20II: I4I, grifos no original).

A relação de semelhança baseada em afinidades de sentidos não se limita a uma mera "compatibilidade" entre o que acontece em um campo com referência a outro. Destacar apenas a "autonomia" dos domínios da atividade social reduz o interesse e a persistência do problema. O conceito de "afinidade eletiva" permite discernir convergências entre fenômenos aparentemente "disparatados". No exemplo clássico de A ética..., seres humanos que buscavam a salvação e a entrada no reino dos céus denotavam valores e modos de vida (a ascese protestante etc.) que favoreceram a acumulação primitiva de capital. Analogias profundas ou os parentescos percebidos em esferas sociais distintas revelam práticas e valores que guardam vínculos de "atração" por semelhança. É o que Löwy chama de "relação interna, rica e significativa entre duas configurações" (Löwy, 20II: I32). Outra observação de Löwy não deve passar desapercebida:

É claro, a afinidade eletiva depende do grau de "adequação" ou de "parentesco" entre as duas formas, mas ela depende também de outros fatores: a afinidade eletiva é favorecida ou desfavorecida por certas condições históricas. Em outros termos, é necessária uma determinada constelação - para utilizar um conceito que Karl Mannheim deslocou com sucesso da astrologia para a Sociologia do Conhecimento - de fatores históricos, sociais e culturais para que se desenrole um processo de attractio electiva, de seleção recíproca, reforço mútuo e, até mesmo, em alguns casos, de "simbiose" de duas figuras espirituais (Löwy, 20ıг: I40).

Cabe lembrar que Weber insistiu, do ponto de vista da metodologia histórica, nas "condições de possibilidade" dos fenômenos, mantendo a perspectiva do que poderia não ter ocorrido. Daí a ressalva de Löwy acerca da afinidade eletiva ser favorecida ou desfavorecida por certas condições históricas.

\section{EVOCAÇÕES}

Nas configurações sociais distintas da arte e da política, aqui situadas no cenário musical do rock and roll e nas contestações marcadas pelos desejos de mudanças na década de I960 e meados dos I970, as condições históricas foram decisivas para a ocorrência de afinidades eletivas. Uma parte expressiva da produção musical do período evocava a intensa movimentação social, porém longe de um engajamento político explícito. 
Bob Dylan, após o comprometimento com causas políticas exibido no início da carreira, tornou-se particularmente reativo às cobranças de engajamento por parte dos fãs e da mídia. Dylan sabia exatamente o que estava fazendo e da sua importância na cultura americana: não se deixou engolir pela atribuição de profeta que iria mostrar o caminho naqueles tempos agitados. Não o faz até hoje e não é difícil encontrar em suas canções a radicalidade de palavras e imagens críticas da vida americana. Sua criação transitou pelas principais fontes da música popular norte-americana e sua poesia trazia (e traz) a força e a radicalidade de um "sentimento do mundo" que tocou gente de todas as idades em todo lugar. A obra desse aparente "renegado" não deixou de sacudir consciências. Daniel Mark Epstein, um de seus biógrafos, autor de A balada de Bob Dylan - um retrato musical, comenta: "Algumas das canções tinham um impacto mensurável sobre os eventos, de um modo que a arte raramente tem" (Epstein, 2012: 104).

As palavras de Dylan atravessaram continentes em várias direções e fixaram de modo particularmente original e denso a experiência daquela geração. Ele nunca deixava barato, mesmo nas canções mais leves e bem-humoradas, em dimensões que repercutiam publicamente e transportavam seus ouvintes para cenários poéticos (além dos encantamentos sonoros) que ultrapassavam os limites do conformismo e da adaptação. Ao longo dos anos reafirmou em depoimentos e entrevistas: "Eu sou feliz só por poder vivenciar as coisas. Eu não preciso ser feliz. A felicidade é uma palavra barata" (Epstein, 20I2: I90). Milhões de fãs gostavam de sua poesia e de sua música, não necessariamente de política, mas eram convidados a partilhar de um ambiente estético que mantinha afinidades eletivas com a inquietação das ruas e as transformações da intimidade.

A letra de "Rainy Day Women \#I2 \& 35", uma canção jocosa que não figurou entre os maiores sucessos de Dylan, merece uma lembrança por tratar das reações à transgressão generalizada vivenciada na época e aludia à possibilidade de contornar com ironia a solidão as punições do conservadorismo:

Well, they'll stone you and say that it's the end.

Then they'll stone you and then they'll come back again.

They'll stone you when you're riding in your car.

They'll stone you when you're playing your guitar.

Yes, but I would not feel so all alone,

Everybody must get stoned ${ }^{\mathrm{I}}$

Epstein observa: "Dylan construiu sua letra em cima da ambiguidade da palavra 'stoned', que pode significar tanto 'apedrejado' quando 'drogado', 'doidão'” (Epstein, 20I2: I88). "Rainy \# I2", cantada de forma desafiadora, contém um breve manifesto à transgressão, em um sonho de liberdade desanu- 
viada da hostilidade repressiva lançada contra comportamentos disseminados na juventude. Garotos e garotas reconheciam com facilidade a mensagem, e outros um tanto mais velhos também. Mesmo os desavisados entendiam a canção e assim adentravam em um terreno em que vicejava o inconformismo, em afinidade com algo que não lhes pertencia previamente.

No universo do rock and roll cabia de tudo, desde as interpretações adocicadas dos Carpenters (uma dupla de irmão e irmã), onde se destacava a belíssima voz de Karen Carpenter, até o coração sangrando de Janis Joplin por um amor nunca alcançado. John Lennon adorava a versão de Karen Carpenter para "Ticket to ride", do disco Help, conexão inusitada entre um dos mais irrequietos e contestadores ídolos do rock com a afinadíssima, bem comportada e típica garota americana. Valores e estilos de vida quase opostos encontravam pontos de contato através da música.

As legiões de admiradores tendiam a se fixar em suas bandas de preferência, mas também não era de se estranhar que muitos transitassem entre os Carpenters ou The Hollies e os Beatles (ou Rolling Stones, The Who, The Doors etc.), em viagens poéticas e sonoras que iam do romantismo ingênuo à vontade de explodir com os limites da vida integrada. Naquele contexto de mudança, as consciências tornavam-se suscetíveis a esses fluxos de sensibilização. No rock and roll, muitas portas estavam abertas aos ouvintes e fãs para a passagem do conformismo ao inconformismo, o que não quer dizer que a travessia fosse inevitável.

Tariq Ali, o paquistanês que foi a mais expressiva liderança estudantil na Inglaterra nos anos 1960, faz um comentário que indica algo no mesmo sentido:

Para alguns, isso e certo tipo de alegre misticismo definem 1968. A política tende a ser ignorada. Ao corrigir esse desequilíbrio, não pretendo afirmar que havia uma muralha da China entre a cultura pop e a política revolucionária. De fato, nos pontos altos do movimento, houve uma mistura forte e inebriante de ambas. Absorvemos um pouco de música e os devotos dos grupos de rock aprenderam um pouco de política (Ali, 2008: 205).

Ali percebe elementos convergentes e análogos entre o espírito de mudança dos anos I960 e meados dos I970 com a volumosa aventura musical do rock and roll. Não se objetivou uma relação "necessária", mas uma "afinidade eletiva" entre a música que fazia sonhar, com palavras e sons, e os desejos e demandas mais amplas que motivavam a ação política.

A convergência entre as duas configurações está na presença de analogias significativas e a similaridade de sentidos que acabaram por aproximá-las. As afinidades eletivas entre o rock and roll e o espírito de mudança e, no limite, com a contestação ao status quo, foi favorecida por uma determinada constelação de fatores históricos, sociais e culturais. O rock and roll fez parte da inspiração estética de milhões de indivíduos e também figurou no imaginário da transformação social de parcelas da juventude. No início dos anos 
I970, o diretor de cinema Martin Scorcese ("uma cabeça rock and roll, sabia as letras de todas as músicas") considerava que "a música era um aspecto crítico do Zeitgeist da época" (Biskind, 2009: 156). Nem sempre é assim.

A banda californiana The Beach Boys nasceu fazendo surf music. Suas canções falavam de garotas, praias, pranchas, namoros e divertimentos da juventude dourada da Costa Oeste americana. Nos anos I960, eles chegaram a disputar com os Beatles os primeiros lugares nas paradas de sucesso. $\mathrm{Na}$ época, já despontava o gênio musical do atormentadíssimo Brian Wilson, que havia fundado o grupo junto com seus irmãos Carl e Dennis, seu primo Mike Love e um amigo chamado Al Jardine. Apesar de graves problemas familiares por força de um pai extremamente severo, aparentemente os Wilson eram rapazes bem ajustados aos prazeres e confortos do american way of life. No entanto, não ficaram imunes à contracultura e entraram de cabeça na "cultura do ácido", o que demarcou uma profunda guinada artística e o simbolismo social em torno da banda.

Brian Wilson ficara vivamente impressionado com o disco Rubber Soul, dos Beatles. A seguir, os Beach Boys gravaram o álbum Pet Sounds, que transportava a experiência juvenil californiana para um cenário de sensibilização através das drogas lisérgicas e expansão dos limites musicais. Pet Sounds se tornou um marco na música popular norte-americana, porém a emulação com os Beatles ganhou sentidos trágicos. Quando Brian ouviu Sgt. Pepper's Lonely Hearts Club Band foi tomado pela obsessão de produzir algo no mesmo nível, que se somou ao seu histórico recente de abalos psíquicos e lhe provocou danos que se alongaram por décadas.

Uma das mais impressionantes realizações de Brian Wilson foi o disco Smile, que levou 37 anos para ser concluído e foi lançado em 2004. Considerado uma obra-prima, Smile conserva passagens originais produzidas na década de ig60 que nunca chegaram ao domínio público. Nesse ínterim, os padecimentos mentais de Brian Wilson paralisaram suas atividades por longos períodos. Paul McCartney, um admirador declarado de Brian Wilson, considera "God only knows" (presente em Pet Sounds) uma das mais belas canções da música popular americana. Em homenagem aos Beach Boys, os Beatles simularam seus vocais em "Back in the USSR", no chamado "Álbum Branco" de I968.

Os Beach Boys não tratavam de política em suas canções, concertos ou entrevistas, mas acabaram por compartilhar a experiência histórica daquela geração no comportamento e nas incursões em novos territórios de experimentação sonora. "Good vibrations", lançada em I966, tornou-se um grande hit que reproduzia as sensações das drogas lisérgicas e se afastava do bom-mocismo de animados jovens sob o sol da Califórnia. Os Beach Boys adentravam a vida "endiabrada". Os rapazes despolitizados, que encantavam as plateias conservadoras pelas melodias e arranjos de voz, ultrapassavam os limites convencionais e estabeleciam afinidades eletivas com aspirações que eles nunca buscaram. 
A fogueira do "comportamento pouco respeitável" já ardia bem alta. Em I968, os Rolling Stones lançaram "Sympathy for the Devil", uma das canções mais famosas e expressivas da incursão por regiões obscuras da mente e da cultura. Gravada entre os dias 4 e Io de junho, ocupava a primeira faixa do disco Beggars Banquet e Jean-Luc Godard documentou os ensaios em seu filme One plus one.

O jornal Rolling Stone, referência no mundo do rock and roll, colocou "Sympathy for the Devil" em $32^{\circ}$ lugar entre as 500 melhores canções de todos os tempos. Após o lançamento do disco, mentes assustadas e o sempre vigilante exército dos moralistas acusaram o grupo de satanismo quando, de fato, a composição abordava as forças da intolerância e da violência que atravessaram o século XX. E, no espírito da época, a sua presença na vida interior dos indivíduos. As frases interpretadas por Mick Jagger mexiam com o "fascismo dentro de nós", como escreveu Michel Foucault. A canção trazia Lúcifer como um cronista autorizado dos crimes, das crueldades, das revoltas e do inconformismo. Perante as tragédias do século, a "simpatia pelo Diabo" estilhaçava o maniqueísmo da moral dominante e ampliava a experiência daqueles que se dispusessem ao embate interior com seus desejos e ímpetos inconfessáveis.

A letra de "Sympathy for the Devil" aborda a Revolução Russa, a Segunda Guerra Mundial e os assassinatos de John e Robert Kennedy:

I stuck around St. Petersburg / When I saw it was a time for a change / Killed the czar and his ministers/ Anastasia screamed in vain... I rode a tank/ Held a general's rank/ When the blitzkrieg raged/ And the bodies stank... I shouted out/ "Who killed the Kennedys?"/ When after all/It was you and me/ (who who, who who).2

A canção iguala os transgressores e os fora-da-lei aos "santos" e "justos", além de não oferecer clemência para aqueles que se creem a salvo das implicações pelas barbaridades cometidas com consentimento. No emblemático ano de 1968 , os policiais e as forças de repressão não podiam ficar de fora:

Just as every cop is a criminal/ And all the sinners saints/ As heads is tails/ Just call me Lucifer / 'Cause I'm in need of some restraint / (who who, who who)... Tell me baby, what's my name / Tell me honey, can ya guess my name / Tell me baby, what's my name / I tell you one time, you're to blame. ${ }^{3}$

A face endiabrada da vida não podia ser escondida atrás das xaropadas do bom-mocismo. Pela voz de Lúcifer/Jagger a moral e as crenças conformis tas pretensamente apaziguadoras dos demônios interiores não ocultavam o fato de que a violência estava perto demais para aqueles que acreditavam que os bons sentimentos tinham morada inequívoca dentro de si. A adesão à ordem e ao bom comportamento não garantia isenção ética às dores provocadas pelas barbaridades do século. Lúcifer rondava a História e a vida rotineira das pessoas, cantava Mick Jagger. A "simpatia pelo Diabo" carregava uma boa dose de afinidades eletivas com as transformações da década. 


\title{
JOHN LENNON E YOKO ONO, VENDEDORES DE SABONETES DA PAZ
}

Nas festas de fim de ano de I969, ao providenciar a instalação de imensos outdoors em doze grandes cidades do mundo com os dizeres "The war is over, if you want it. Happy Christmas, John and Yoko", o casal produziu um contraste com as manchetes diárias que anunciavam as tragédias da guerra no Vietnã. A paz imaginada tornava-se um chamamento à mobilização mundial de repúdio ao conflito. Inúmeras correntes de opinião influenciavam esses esforços, mas a atuação de John e Yoko alcançou a esfera pública em dimensões globais com destacada eficácia propagandística.

Anteriormente eles já haviam encenado o bed-in for peace na suíte presidencial do Hotel Hilton de Amsterdam. De pijamas durante uma semana, em cruzada de amor contra a guerra e cercados pela mídia mundial obcecada pela possibilidade de cenas de sexo ou algo apimentado, John e Yoko monopolizaram a atenção da mídia mundial "à maneira de Gandhi" (Norman, 2009: 594) onde não faltaram música e respostas irônicas às perguntas, muitas vezes tolas, de jornalistas atônitos com a originalidade da manifestação. Consagrados jornalistas atribuíam a John apenas o papel de "palhaço", no qual ele se sentiu inteiramente à vontade ao ser lido ou visto por milhões de pessoas no mundo inteiro durante vários dias.

Com perfeita clareza sobre a utilização da mídia como produtora de celebridades e diluição dos conteúdos pela própria dinâmica da sociedade do espetáculo, John declarou que queria "vender a paz como se vende sabonete":

\begin{abstract}
Hoje precisamos de outros métodos - o negócio é vender, vender, vender. Se quisermos vender a paz, vamos ter de vendê-la como sabonete. [A mídia] Coloca a guerra no ar todo dia, não só nos noticiários, mas nos velhos filmes de John Wayne e em toda porcaria de filme que a gente assiste, guerra, guerra, matar, matar, matar. Então dissemos: "Vamos colocar um pouco de paz, paz, paz nas manchetes, só para variar"... Por motivos conhecidos apenas por elas, as pessoas publicam o que eu digo. E estou dizendo "Paz"... Cristo fazia milagres para propagar sua mensagem. Pois bem, o milagre hoje são as comunicações, por isso vamos usá-las (Lennon apud Norman, 2009: 594).
\end{abstract}

Tariq Ali afirmou que em poucas semanas John Lennon e Yoko Ono haviam propagado a causa da paz em dimensões bem mais amplas do que as alcançadas por ele e seus companheiros em anos de trabalho organizativo. $O$ casal aproveitara o lugar destacado de John no pedestal das celebridades para despertar a atenção do público mundial para a interrupção dos combates e a retirada das tropas americanas do Vietnã.

Ao bed-in de Amsterdam seguiu-se outro em Montreal, com a mesma repercussão. Um Beatle de pijama fez esse frenesi todo. Mensagens políticas pela paz eram trazidas para uma cena de intimidade desarmada, em contras- 
te com as vestimentas usadas nos comícios e manifestações. O "palhaço" Lennon, junto com Yoko, tocava violão, desconcertava com declarações irônicas, anunciava a necessidade do amor e conduzia um ritual que nada tinha a ver com a seriedade militante, acompanhado minuto a minuto pelos meios de comunicação de massa.

A linguagem do bed-in mostrou-se inovadora em relação aos métodos de propaganda política até então utilizados, e também bebia dos happenings e das formas de contestação da contracultura. Mas, longe da ingenuidade e de um suposto teatralismo narcísico, John Lennon pensava na eficácia política desses atos:

Em Paris, as conversações da paz sobre o Vietnã só chegaram ao ponto de decidir o formato da mesa ao redor da qual se sentariam os delegados. E essas tratativas vêm ocorrendo há meses. Em uma semana na cama, nós conseguimos muito mais... Uma velhinha de Wigan ou Hull escreveu ao Daily Mirror perguntando se podiam publicar fotos minhas e de Yoko na primeira página com mais frequência. Ela disse que há muito tempo não ria tanto. Isto é fabuloso! Era o que queríamos. Quero dizer, é engraçado quando duas pessoas que vão para a cama na sua lua-de-mel podem sair nas primeiras páginas de todos os jornais durante uma semana. Eu não me importaria em ficar conhecido como o palhaço do mundo. Não estou em busca de epitáfios (Lennon apud Norman, 2009: 595).

Mensagens vendidas como sabonetes para a paz e o humor das idosas de Wigan faziam a delícia da atuação pouco convencional de John e Yoko. Não se imagina que Tariq Ali e seus companheiros conseguissem angariar a simpatia das velhinhas moradoras dos arredores das grandes cidades inglesas. Apesar do massacre sofrido anos antes na América, quando afirmou que os Beatles eram mais populares que Jesus, John Lennon, o ídolo do rock and roll, conquistava adeptos em todo o mundo para a causa da paz.

Apesar das críticas, que não foram poucas, a pregação de John Lennon contou com um grau de confiabilidade semelhante às suas realizações artísticas que haviam encantado tanta gente. Ele e Yoko jamais quiseram ocupar um lugar diverso daquele reservado aos artistas que se manifestavam livremente sobre o rumo dos acontecimentos e não se comprometeram duradouramente com nenhuma corrente ideológica.

Na segunda metade da década de I970, em outra guinada, John Lennon recolheu-se ao lar, acompanhou dedicadamente os primeiros anos de vida de seu filho Sean e passou algum tempo sem gravar. Ele fazia um acerto de contas consigo mesmo e deixava os negócios nas mãos de Yoko Ono. Precisava tratar de ser um pai de verdade, algo que não havia conseguido com Julian, fruto de seu casamento com Cynthia Powell. Ele buscava fortalecer laços em sua vida privada depois do sucesso mundial, muito dinheiro, mulheres à vontade, drogas em profusão e instabilidade emocional. 
Para dar conta das reviravoltas das posições de John Lennon, o conceito de "esfera pública" merece ser aplicado de forma mais larga, pois ele não pretendia vocalizar uma "racionalidade moralmente pretensiosa". Na obra de Jürgen Habermas, os portadores dos discursos parecem perseverar de forma idealizada e contínua em suas posições até a consagração do melhor argumento no debate público, quiçá avançando na direção de uma "comunicação não distorcida", destino esperançoso compreendido nas ideias do pensador alemão. Uma breve definição assim está formulada em Mudança estrutural da esfera pública:

Ao mesmo tempo, tudo o que, sob tais condições, resulta do tirocínio público, pretende ter racionalidade; de acordo com a sua própria concepção, uma opinião pública nascida da força do melhor argumento, demanda aquela racionalidade moralmente pretensiosa que busca conjuminar o certo com o correto (Habermas, 1984: 72).

Sem se deixar subtrair em nenhum momento do papel de contestador, ou de "palhaço", as atitudes e opiniões de Lennon foram marcadas pela descontinuidade e pela surpresa. Inventava, desafiava, desistia, expunha suas inquietações interiores e recorria com frequência a doses de autoironia que o tornavam um portador extravagante e, nesse sentido, pouco canônico, de discursos na esfera pública. Nesse aspecto, talvez a contribuição da cultura do rock and roll tenha sido a destituição de certa solenidade na manifestação de argumentos e impressões para audiências mundiais. Lideranças de movimentos, políticos, jornalistas, cientistas, literatos, polemistas e intelectuais de diversas origens, que povoam a imagem da esfera pública de Habermas, em nada se parecem com o Beatle que vendia sabonetes para a paz ou despertava o riso frouxo das velhinhas inglesas.

O percurso de Lennon pode caber nas palavras de Zygmunt Bauman, quando este afirma que a possibilidade de uma "comunicação não distorcida" (com sua perfeição pelo consenso e exclusão do desacordo) é um "sonho de morte que cura radicalmente os males da vida de liberdade" (Bauman, I998: 249). Bauman, que considera Habermas um pensador indispensável à compreensão da modernidade, acentua, em outro sentido, a tolerância e a presença do diverso em que o embate das opiniões não projeta uma síntese que unifica os atores interessados na disputa:

Se o monoteísmo significa falta de liberdade, a liberdade nascida da realidade politeísta não implica, em oposição a seus detratores, niilismo. Ser livre não significa não acreditar em nada: significa é acreditar em muitas coisas - demasiadas para a comodidade espiritual de obediência cega; significa estar consciente de que há demasiadas crenças igualmente importantes e convincentes para a adoção de uma atitude descuidada ou niilista ante a tarefa da escolha responsável entre elas; e saber que nenhuma escolha deixaria o escolhedor livre da responsabilidade pelas suas consequências - e que, assim, ter escolhido não significa ter determinado a matéria de escolha de uma vez por todas, nem o direito de botar sua consciência para descansar (Bauman, 1998: 249). 
Bauman resiste à ideia da polifonia ultrapassada por crenças aprimoradas que acabam por assegurar a regra do consenso. A polifonia é o próprio campo de imaginação do viver, que em nada se parece com a "comodidade espiritual" de patamares de racionalidade que se sucedem na produção de consensos, mesmo que transitórios. A premissa de Bauman é a permanência e onipresença da ambivalência na modernidade, que o inclina a rejeitar projetos ordenadores com forte parentesco com o "ideal de perfeição" sob garantias de uma racionalidade expansiva.

Em outra vertente da crítica, Anthony Giddens, no ensaio "O guru improvável: relendo Marcuse", questiona o uso apenas "metodológico" da teoria psicanalítica de Freud como modelo para situações dialogais na sociedade por parte de Habermas:

Habermas deixou poucas indicações do quanto ele aceitava o conteúdo dos escritos de Freud. A esse respeito, sua apropriação de Freud contrasta claramente com a de Marcuse, e isso tem consequências sobre o trabalho posterior de Habermas. Pois o conceito de situação ideal do discurso, interessante como possa ser em si mesma, mantém-se num nível especialmente cognitivo. O que acontece com afeto, sexualidade, amor, ódio e morte? (Giddens, I998: 276, grifo do autor).

O ponto de apoio da elaboração de Giddens é o conceito de "reflexividade" entendido como incorporação de informação renovada em todos os domínios da vida social e a capacidade de monitoração reflexiva da ação, em uma teoria da reprodução social que recupera "a qualificação e o caráter passível de aprendizado da participação cotidiana dos atores nas práticas sociais" (Giddens, I998: 310), como aparece no texto "Sobre trabalho e interação em Habermas". A démarche teórica não se desfaz da racionalidade argumentativa do discurso, mas chama a atenção para o que a ultrapassa.

Portanto, para Bauman e Giddens, a "situação ideal do discurso" ou a "comunicação não distorcida" se caracteriza por uma projeção idealizada dos efeitos da racionalidade sobre o debate público. A vida da liberdade, das convicções e variedades de discursos não converge para um patamar em que as distorções estarão finalmente superadas, ou que um desejado consenso seja obtido através de uma aquisição de verdade laboriosamente debatida e retificada na esfera pública pelo encontro dos argumentos e contra-argumentos. O que se quer destacar aqui é a crítica à "perfeição" e à autorização de sua presença pública como porvir pretendido.

Como lidar, então, com um discurso que se desmente, que se autoironiza, e, na sua pretensão de avançar politicamente, não pretende mais do que uma presença temporária na esfera pública? A participação social de John Lennon sempre funcionou à base de fantasia, imaginação, provocação, incitação e do exercício de uma radicalidade que se encerrava em si mesma e deixava a lembrança para um próximo episódio onde quiçá poderia ser exer- 
cida novamente. No entanto, em virtude da ampla popularidade obtida através do rock, alcançava uma eficácia superior a muitos discursos devidamente instalados nas redes dialógicas da sociedade. A voz de John Lennon, ouvida por gente de todo lugar, escapava aos formatos políticos já consagrados.

Em sua reclusão, a partir de meados dos anos I970, John Lennon aparentava estar à margem de tudo. A atitude provocou decepções e críticas generalizadas, geralmente atribuídas ao seu casamento com Yoko Ono, às quais ele respondeu na canção "Watching the wheels", do disco Double fantasy, lançado em I980, ano de sua morte:

People say I'm crazy doing what I'm doing

Well they give me all kinds of warnings to save me from ruin

When I say that I'm o.k. well they look at me kind of strange

Surely you're not happy now you no longer play the game

People say I'm lazy dreaming my life away

Well they give me all kinds of advice designed to enlighten me

When I tell them that I'm doing fine watching shadows on the wall

Don't you miss the big time boy you're no longer on the ball

I'm just sitting here watching the wheels go round and round

I really love to watch them roll

No longer riding on the merry-go-round

I just had to let it go

Ah, people asks me questions lost in confusion

Well I tell them there's no problem, only solutions

Well they shake their heads and they look at me as if I've lost my mind

I tell them there's no hurry

I'm just sitting here doing time

I'm just sitting here watching the wheels go round and round

I really love to watch them roll

No longer riding on the merry-go-round

I just had to let it go

I just had to let it go

I just had to let it go

John parecia bastante satisfeito por estar em casa "fazendo pão" e cuidando de Sean. Desta vez suas preocupações eram outras e fazia eco às palavras de Yoko Ono: "Ao libertar as pessoas da vida familiar, eles as jogam na armadilha do capitalismo. Para acelerar o capitalismo, é melhor que todos sejam solteiros. Não há lugar para emoções da família e das relações pessoais" (Ono apud Scheff, 20I2: 58). 
Se ele havia aderido às iniciativas políticas de Tariq Ali, Abbie Hoffman, Jerry Rubin e se aproximado dos Panteras Negras e posteriormente não poupara críticas às demandas por dinheiro e incentivo à violência, não seria agora que se submeteria a injunções exteriores. Continuava a opinar livremente e, na sua irresistível tendência de mudar, Lennon ironizou sua canção "Power to the people", que foi cantada em grandes manifestações de massa contra a guerra no Vietnã, "composta em um estado de dormência em que eu queria ser amado por Tariq Ali e sua turma" (Lennon apud Sheff, 20I2: 273). Disse com todas as letras que não faria algo assim de novo.

John Lennon jamais dissolveu a sua condição de artista e o exercício amplo de criação mesmo durante o comprometimento mais intenso com causas políticas ou nos laços com lideranças expressivas de movimentos da época. A sua margem de liberdade não suportava "opiniões convenientes", mesmo que essa liberdade acabasse por denunciar os seus próprios passos mal dados. Tudo isso era exposto publicamente e, portanto, trazido ao debate das opiniões.

O irrequieto e sempre insatisfeito Lennon continuava fiel ao inconformismo que encarnou o espírito desafiador das ideias e esperanças mais contundentes de sua geração. Quando resolveu se retirar, o fez com a independência e a liberdade de sempre. No jogo permanente e dinâmico da argumentação e contra-argumentação na esfera pública, os "palhaços" do rock and roll contribuíram para posturas que ampliaram o escopo das opiniões e das ações.

Recebido em II/II/20I3 | Aprovado em 04/06/20I4

Luis Carlos Fridman é doutor em Sociologia pelo Instituto Universitário de Pesquisas do Rio de Janeiro (IUPERJ), professor titular do Departamento de Sociologia e do Programa de Pós-Graduação em Sociologia e Direito da Universidade Federal Fluminense (PPGSD-UFF), e pesquisador da FAPERJ e do Coletivo de Estudos sobre Violência e Sociabilidade (CEVIS). É autor de, entre outros, Vertigens pós-modernas - configurações institucionais contemporâneas (2000) e O jardim de Marx (2003). Publicou recentemente os ensaios "O rock dos anos 60 e as utopias privatizadas da contemporaneidade" (2012), "Rock e revolução nos anos 6o" (2013) e "Vaias para Bob Dylan" (2014). 


\section{NOTAS}

I Bem, te apedrejarão e dirão que é o fim / Então eles te apedrejarão e depois voltarão / Eles te apedrejarão quando você estiver andando em seu carro / Eles te apedrejarão quando você estiver tocando seu violão / Sim, mas eu não me sentirei tão sozinho / Porque todo mundo tem que ficar doidão.

2 Estava por perto em São Petersburgo / Quando vi que era tempo de uma mudança / Matei o Czar e seus ministros / Anastásia gritou em vão... Montei em um tanque / Mantive a posição de General / Quando a blitzkrieg estourou / E os corpos federam... Gritei alto / "Quem matou os Kennedys?" / Quando, no final das contas / Fui eu e você/ (Quem? Quem?)

3 Assim como todo policial é um criminoso / E todos os pecadores são santos / E cara é coroa / Simplesmente me chame de Lúcifer / Porque preciso de alguma restrição / (Quem? Quem?)... Diga-me amor, qual é o meu nome / Diga-me querida, pode adivinhar meu nome / Diga-me amor, qual é o meu nome / Eu direi uma vez, você é a culpada.

4 As pessoas dizem que eu sou louco por fazer o que faço / Bem eles me dão todos os tipos de conselhos para me salvar do fracasso / Quando eu digo que eu estou o.k, bem eles olham para mim de um jeito estranho / Com certeza você não está feliz agora que você já não joga (mais) o jogo / As pessoas dizem que eu sou preguiçoso fazendo de minha vida apenas sonhos / Bem eles me dão todos os tipos de conselho feitos para me iluminar / Quando eu lhes falo que eu estou bem assistindo sombras na parede / Você não sente falta do menino daquele tempo grandioso, que você não é mais?

Eu estou apenas sentado aqui olhando o movimento / Eu realmente adoro ver o movimento / Já não monto no carrossel / Eu apenas tive que deixar rolar

Ah, as pessoas fazem perguntas, perdidas em confusão / Bem, eu lhes digo que não há problemas, só soluções, / Bem, eles balançam suas cabeças e me olham como se eu tivesse perdido a razão / Eu lhes digo que não há nenhuma pressa / Eu apenas estou sentado aqui "fazendo hora" 
Eu estou apenas sentado aqui olhando o movimento / Eu realmente adoro ver o movimento / Já não monto no carrossel eu apenas tive que deixar ir / Eu apenas tive que deixar rolar / Eu apenas tive que deixar rolar / Eu apenas tive que deixar rolar.

\section{REFERÊNCIAS BIBLIOGRÁFICAS}

Aitkenhead, Decca. (200o). Em busca do espaço público. In: Em busca da política. Rio de Janeiro: Zahar.

Ali, Tariq. (2008). O poder das barricadas - uma autobiografia dos anos 6o. São Paulo: Boitempo.

Bauman, Zygmunt. (2000). Em busca da política. Rio de Janeiro: Zahar.

Bauman, Zygmunt. (I998). O mal-estar da pós-modernidade. Rio de Janeiro: Zahar.

Biskind, Peter. (2009). Como a geração sexo-drogas-e-rock'n'roll salvou Hollywood. Rio de Janeiro: Intrínseca.

Epstein, Daniel Mark. (2012). A balada de Bob Dylan - Um retrato musical. Rio de Janeiro: Zahar.

Giddens, Anthony. (1998). O guru improvável: relendo Marcuse. In: Política, sociologia e teoria social. Encontros com o pensamento social clássico e contemporâneo. São Paulo: Ed. Unesp, p. 263-28I.

Giddens, Anthony. (1998). Sobre trabalho e interação em Habermas. In: Política, sociologia e teoria social. Encontros com o pensamento social clássico e contemporâneo. São Paulo: Ed. Unesp, p. 297-313.

Gould, Jonathan. (2009). Can't buy me love - Os Beatles, a Grã-Bretanha e os Estados Unidos. São Paulo: Larousse.

Habermas, Jürgen. (I984). Mudança estrutural da esfera pública. Rio de Janeiro: Tempo Brasileiro.

Hobsbawn, Eric J. (2009). História social do jazz. São Paulo: Paz e Terra.

Hobsbawn, Eric J. (2002). Tempos interessantes. Uma vida no século XX. São Paulo: Companhia das Letras.

Jameson, Fredric. (I996). Pós-modernismo. A lógica cultural do capitalismo tardio. São Paulo: Ática. 
ROCK AND ROLL, JOHN LENNON E A ESFERA PÚBLICA

540

Löwy, Michael (20II). Sobre o conceito de "afinidade eletiva" em Max Weber. Plural, I72, p. I29-I42.

Löwy, Michael. (1989). Redenção e utopia. São Paulo: Companhia das Letras.

Norman, Philip. (2009). John Lennon. São Paulo: Companhia das Letras.

Matos, Olgária Chain Féres. (I998). Tardes de maio. Tempo Social, Io/2, p. I3-24.

Mehreb, Rodrigo. (2012) O som da revolução - Uma história cultural do rock I965-1969. Rio de Janeiro: Civilização Brasileira.

Sheff, David. (2012). A última entrevista do casal John Lennon e Yoko Ono. Rio de Janeiro: Nova Fronteira. 
Palavras-chave

Anos I960;

Rock and roll;

Política;

Cultura;

"Afinidades eletivas".
ROCK AND ROLL, JOHN LENNON

\section{E A ESFERA PÚBLICA}

\section{Resumo}

O artigo se propõe a distinguir as "afinidades eletivas" entre o rock and roll e a atmosfera de contestação dos anos I960. Retorna à intensa atividade criativa da música popular naqueles anos e a imensa repercussão que o rock alcançou em enormes parcelas da juventude para examinar compatibilidades mais sutis entre a política e a cultura, para além de vínculos "necessários" entre as duas esferas sociais. Nesse sentido, destaca bandas e sugere interpretações para algumas canções, ao lado de se ater a trajetos particularmente significativos, como o de John Lennon, para discutir a influência da música na esfera pública, que ampliou o escopo das opiniões e das ações.

\section{ROCK AND ROLL, JOHN LENNON} AND THE PUBLIC SPHERE

Keywords

\section{Abstract}

I960s; The article aims to distinguish the "elective affinities"

Rock and roll;

Politics;

Culture;

"Elective affinities". between rock and roll and the atmosphere of dispute of the I96os. It returns to the intense creative activity of popular music in those years and to the enormous impact rock had on a significant portion of youth in order to examine subtler compatibilities of politics with culture, in addition to the "necessary" connections between these two social spheres. In this sense, it highlights some bands and analyzes some songs as well as significant trajectories, such as John Lennon's, in order to discuss the influence of music on the public sphere, which broadened the scope of opinions and actions. 